\title{
Impact of Changes in Groundwater Extractions and Climate Change on Groundwater-Dependent Ecosystems in a Complex Hydrogeological Setting
}

\author{
Jolijn van Engelenburg ${ }^{1,2}$ (D) Rosa Hueting ${ }^{1,2,3}$ • \\ Sjoerd Rijpkema ${ }^{1}$ - Adriaan J. Teuling ${ }^{4}$. \\ Remko Uijlenhoet $^{4}$ • Fulco Ludwig ${ }^{2}$
}

Received: 7 March 2017 / Accepted: 29 August 2017 /

Published online: 12 September 2017

(C) The Author(s) 2017. This article is an open access publication

\begin{abstract}
Climate change and other future developments can influence the availability of groundwater resources for drinking water. The uncertainty of the projected impact is a challenge given the urgency to decide on adaptation measures to secure the drinking water supply. Improved understanding on how climate change affects the groundwater system is necessary to develop adaptation strategies. AZURE is used, a detailed, well-calibrated hydrological model to study the projected impact of climate change scenarios on the large Veluwe aquifer in the Netherlands. The Veluwe area is an important source of drinking water. However, some existing groundwater extractions in the area affect nearby groundwaterdependent ecosystems. Redistribution of the licensed extraction volumes of these sites is considered to reduce the impact on these ecosystems. The projected impact of climate change and redistribution to groundwater levels is studied. The research shows that in a slowly responding large aquifer the projected climate change may cause rising groundwater levels despite the projected increase in summer dryness. The results indicate that this impact may exceed the impact of redistribution of extraction volumes. In addition, it is shown that the combined effect strongly depends on local conditions, thus highlighting the need for highresolution modelling.
\end{abstract}

Jolijn van Engelenburg

jolijn.vanengelenburg@wur.nl

Vitens NV, P.O.Box 1205, 8001BE Zwolle, Netherlands

2 Water Systems and Global Change Group, Wageningen University \& Research, P.O.Box 47, 6700 AA Wageningen, Netherlands

3 Arcadis Nederland B.V, P.O.Box 33, 6800 LE Arnhem, Netherlands

4 Hydrology and Quantitative Water Management Group, Wageningen University \& Research, P.O.Box 47, 6700 AA Wageningen, Netherlands 
Keywords Climate change - Groundwater resources · Drinking water - Desiccation · Groundwater extraction · Veluwe · Hydrological modelling

\section{Introduction}

Groundwater resources are often the preferred source for drinking water supply. Groundwater is considered less vulnerable to pollution than surface water and groundwater quality is usually very stable (Broers and Lijzen 2014). However, groundwater extractions can have an impact on groundwater levels, potentially affecting other water use, such as by agriculture and groundwater-dependent ecosystems. In areas where groundwater systems are likely to be affected by climate change, sustainable groundwater management is challenging and complex and tools to support decisions on improving the long-term sustainability of a groundwater extraction could be of help (Carmona et al. 2013).

Many climate change studies on water resources ignored groundwater and focused on surface water (Gleeson et al. 2012b). Recent studies, however, have shown that groundwater resources are potentially vulnerable to climate change too (Gleeson et al. 2012a; Gleeson et al. 2010; Van der Knaap et al. 2014; De Graaf et al. 2017). Climate change may cause a deterioration of valuable groundwater-dependent ecosystems through desiccation, but can also influence groundwater extractions, e.g. for drinking water supply. Improved understanding on how climate change affects the hydrological system, including groundwater, is necessary to develop adaptation strategies.

Due to the complexity of groundwater systems and limited data availability it is difficult to assess the impact of climate change on groundwater systems. In this research a detailed, well-calibrated (geo)hydrological model is used to study the projected impact of climate change scenarios on a large aquifer in the Netherlands, which can help understand the impact of climate change to similar hydrological systems under similar climatological conditions.

In the Netherlands the projected climate change can be broadly characterized as an increase in precipitation in winter and an increase in summer drought due to higher temperatures and a change in summer precipitation patterns (Van den Hurk et al. 2014). This trend is already visible in the meteorological data (Daniëls 2016). In the Netherlands the increase of precipitation surplus in winter will partially discharge through the surface water system and therefore only partially recharge the groundwater system. In summer the projected temperature rise and change in precipitation pattern may cause an increase in evapotranspiration and a decrease in phreatic groundwater levels. Climate change in the Netherlands is therefore expected to cause stronger desiccation of groundwater-dependent ecosystems. Currently many Dutch ecosystems experience desiccation from decreasing summer groundwater levels (Runhaar et al. 1996), so there is concern that climate change will cause a further deterioration of valuable groundwaterdependent ecosystems (Witte et al. 2012, 2014).

Climate change and other future developments, such as land use change and population growth, can influence not only the availability of groundwater resources for drinking water, but also the drinking water demand (Kumar et al. 2016b). The uncertainty of the impact interferes with the urgency to decide on adaptation measures concerning drinking water supply. In addition, adequate adaptation of drinking water systems to these kinds of long-term developments is complicated and involves not only technical, but also social, political and economic aspects (Kloosterman 2015; Staben et al. 2015; Zwolsman et al. 2014). Therefore, it is 
important to assess the effect of adaptation measures, also regarding climate change, before these measures are implemented.

The Veluwe area is a slightly elevated area in the central part of the Netherlands (Fig. 1). The groundwater in the Veluwe area is an important source of drinking water for the country. However, some drinking water extractions have negative impacts on groundwater-dependent ecosystems. To reduce impacts, partial redistribution of extraction volumes between existing extraction sites within the Veluwe area is considered. Evaluating the effect of such a redistribution on groundwater levels in the hydrological system of the Veluwe area by using a state-ofthe-art groundwater model combined with climate change scenarios will help to inform decisions on the suitability and effectiveness of the considered measure. For the Veluwe area the AZURE model is available, which has already been calibrated and validated by De Lange and Borren 2014). The availability of this model offers a unique opportunity for a detailed study of the impacts of different climate change scenarios and adaptation measures. To the best of our knowledge this is one of the first studies that uses a detailed geohydrological model to compare the projected impact of climate change and adaptation measures on drinking water extraction.

The goal of this study is to assess the projected impact of climate change on the hydrology of the Veluwe area and to compare this to the impact of redistribution of existing drinking water extraction volumes in the Veluwe area by using a state-of-the-art hydrological model.

\section{The Veluwe Area}

The Veluwe area is part of a moraine complex dating back to the Saalien glacial period in the Pleistocene (Rutten 1960; Gehrels 1999). The hydrological system can be seen as a large sandy aquifer of up to $200 \mathrm{~m}$ depth, with a thick unsaturated zone reaching up to a maximum depth of $60 \mathrm{~m}$. The elevated part of the system forms a large infiltration area that recharges the aquifer.

The groundwater system of the Veluwe is a slow-responding system (Gehrels 1999; Kumar et al. 2016a) because in this area there is only a limited surface water system and the groundwater levels are deep below the soil surface. Groundwater level fluctuations in this area are characterized by low frequency fluctuations with a large amplitude (Fig. 1, lower inset). Around the edges of the elevated ridge the groundwater level is much shallower. Here seepage zones developed and groundwater level fluctuations are higher in frequency and have a smaller amplitude (Fig. 1, upper inset). The groundwater levels are not continuous due to the presence of tilted clay layers, causing a discontinuous pattern that obstructs groundwater flow (Gehrels 1999; Verhagen et al. 2014), especially along the steep eastern and southern edges. Although detecting tilted clay layers is difficult, some of them can be located where significant jumps in hydraulic heads are measured on both sides of a tilted clay layer (Person et al. 2007; Van Engelenburg et al. 2012). However, modelling the hydrology of these edges is complicated (Van Engelenburg et al. 2012).

The central part of the Veluwe is rich in nature like woodland, heath and sand drifts. Due to the hydrogeological structure of the system most of these ecosystems are rainwater-dependent (Yousefpour et al. 2015). In contrast to this, the ecosystems at the edges of the area are groundwater-dependent.

The presence of shallow groundwater and seepage zones along the edges of the Veluwe caused the historical development of a man-made drainage system of brooks and springs which was traditionally used for economic exploitation by watermills (Menke and Meijer 2007). These brooks and springs are mainly dependent on groundwater levels. In the Veluwe 

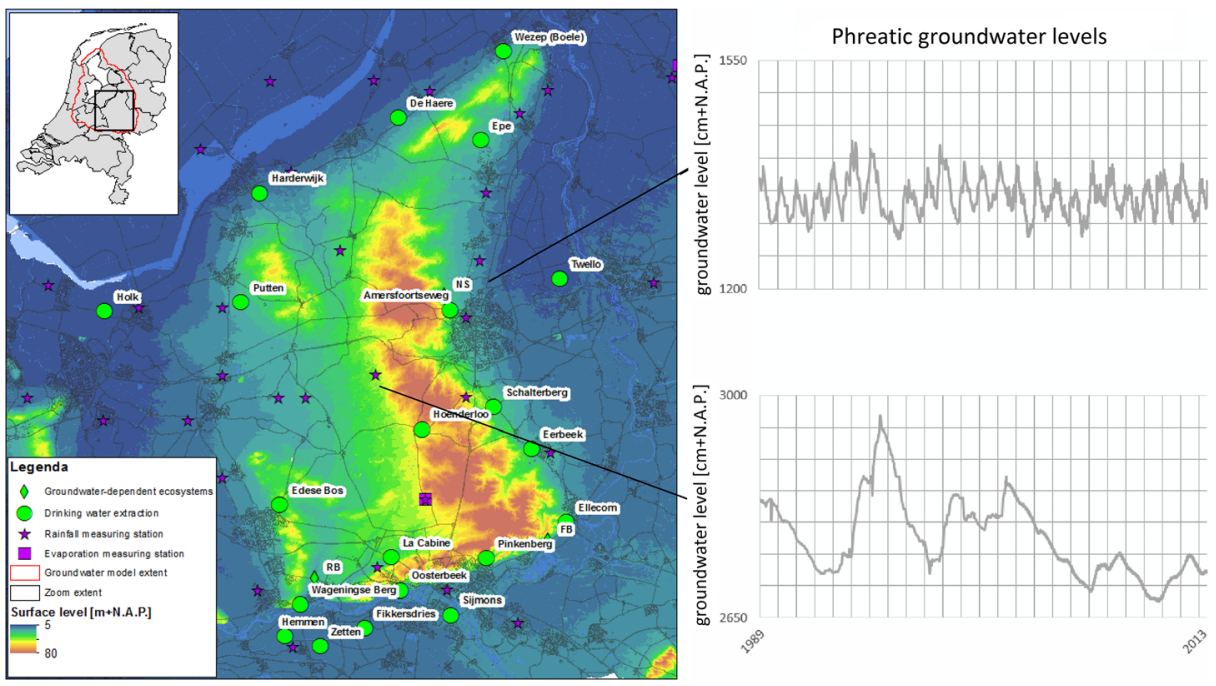

Fig. 1 Map of the Veluwe area with the locations of groundwater extraction sites including Amersfoortseweg (AM), Ellecom (EL), La Cabine (LC) and Hoenderloo (HO), the groundwater-dependent ecosystems NS (Nieuwe Sprengen), FB (Faissantenbos) and RB (Renkum Brooks), the model area and meteorological stations. The insets show the dynamics of the phreatic groundwater levels in two monitoring wells: near Apeldoorn, near the edge of the Veluwe system (upper inset, fast response) and near Radio Kootwijk, in the centre of the Veluwe system (lower inset, slow response)

area groundwater was extracted for urban drinking water supply systems, starting from the early twentieth century. The first extractions were located at the edges of the area, where the groundwater was easily reached. Currently drinking water is extracted from groundwater originating from the Veluwe area at 21 sites (Fig. 1).

Verhagen et al. (2014) estimated that on a yearly basis $90 \times 10^{6} \mathrm{~m}^{3}$ of groundwater is extracted from the Veluwe system for drinking water, nearly $8 \%$ of the average annual precipitation on the area. In comparison, the average annual reference evaporation during the period 1981-2010 is roughly $65 \%$ of the average annual precipitation (Fig. 2). Compared to the annual recharge of the Veluwe groundwater system the impact of the drinking water extraction to the system as a whole is still relatively small. However, locally the impact can be considerable, because most of the drinking water extractions are located near the edges of the Veluwe, sometimes near valuable groundwater-dependent ecosystems or historical brooks and springs.

Most of the drinking water extraction sites, however, do not affect valuable groundwaterdependent ecosystems or measures have already been taken to compensate for the effect. There are three drinking water extraction sites (Amersfoortseweg (AM), Ellecom (EL) and La Cabine (LC)) where compensation is still considered, which were included in this research project because of their relation to a nearby groundwater-dependent ecosystem (Fig. 1). A fourth extraction site, Hoenderloo (HO), was selected because expansion of the extraction volume at this site will probably not affect groundwater-dependent ecosystems. HO is located near the central part of the Veluwe, where the ecosystems depend on rainwater.

AM affects nearby groundwater-dependent artificial spring systems. To compensate for the impact of AM on these springs locally extracted groundwater is supplemented to some of the springs, except the 'Nieuwe Sprengen' system (NS).

The Faissantenbos (FB) near EL is a groundwater-dependent woodland ecosystem, which needs calcareous seepage water. The impact of groundwater extraction at EL amplifies the 

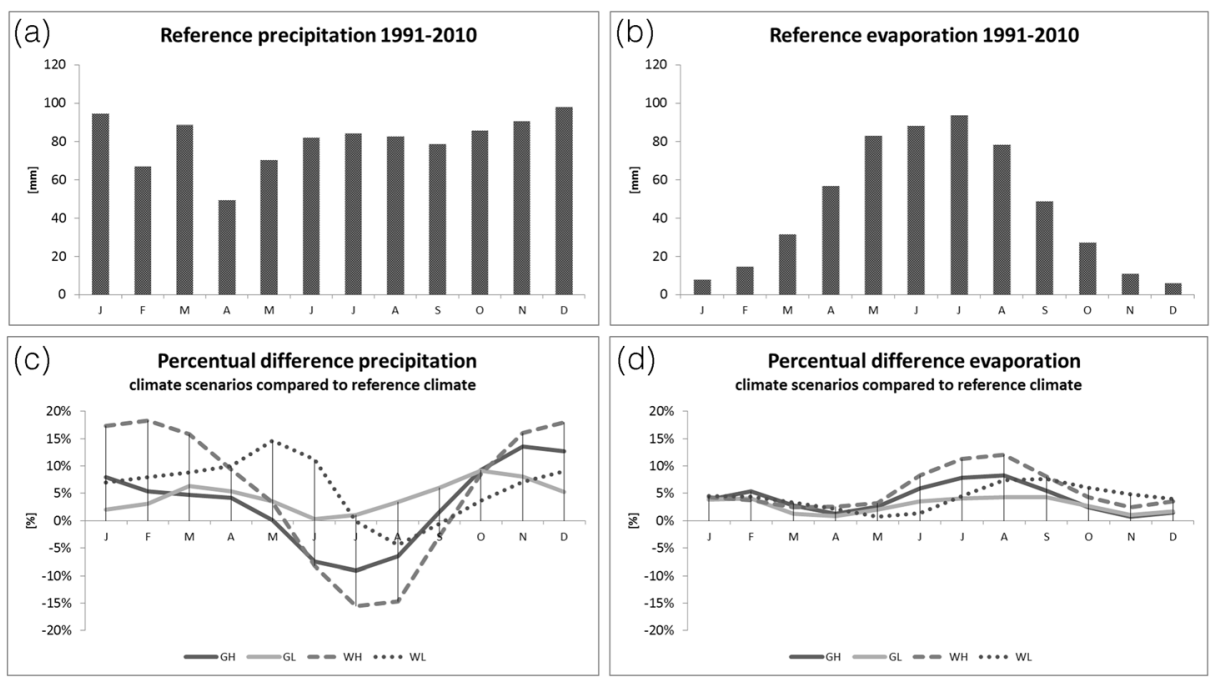

Fig. 2 Reference precipitation and evaporation and projected relative change according to the KNMI'14 climate scenarios. Reference precipitation (a) and reference evaporation (b) are the average monthly precipitation and evaporation [mm] in the reference period (1991-2010) for the meteorological station (a) Apeldoorn and (b) Deelen; KNMI'14 climate scenarios percentage of change is the percentage of change [\%] according to each KNMI'14 scenario for 2050 relative to the reference precipitation (c) and evaporation (d); for detailed information see https://data.knmi.nl/datasets

impact of the agricultural drainage, which caused a decrease of seepage flows towards the ecosystem (Skaggs et al. 1994).

The Renkum Brooks system (RB) that is related to LC consists of man-made brooks. Due to decreasing groundwater levels and deterioration of the brooks the current discharge of the system is now considered too small to meet the ecological goals.

\section{Method}

\subsection{Model}

To estimate the hydrological impact of climate change and the selected adaptation measures the existing AZURE-model (De Lange and Borren 2014; Hekman et al. 2014) was used. AZURE uses MODFLOW for saturated groundwater flow (Harbaugh et al. 2000) and MetaSWAP for the unsaturated groundwater zone (Van Walsum and Groenendijk 2008; Van Walsum and Veldhuizen 2011). The input variables in AZURE are designed to be used at a minimal resolution of $25 \mathrm{~m}$, but the model can be run at a coarser spatial resolution. It can be used for both transient and steady-state calculations. In AZURE the most recent information regarding the geology of the Veluwe area is used (De Lange and Borren 2014) and the model has been calibrated using the available time series of data on precipitation, temperature and groundwater levels. In general the results of the AZURE model compare well to the observed groundwater levels. (De Lange and Borren 2014 and De Lange et al. 2014).

Comparing the results to the observed values, on average the median (p50) of the modelled 1995-2005 groundwater level time-series is slightly lower than observed, especially in the elevated areas. Approximately $20 \%$ of the modelled groundwater levels are $0.5 \mathrm{~m}$ lower than 
the observed levels, again mainly in the elevated areas. Less than $10 \%$ is $0.5 \mathrm{~m}$ higher than the observed values, spread out over the whole model area. A detailed description of AZURE is available in the full report of De Lange and Borren (2014) and to the National Hydrological modelling Instrument NHI (http://www.nhi.nu), which is a Dutch framework of hydrological models including AZURE (Delsman et al. 2008; De Lange et al. 2014).

\subsection{Climate Scenarios in the Netherlands}

The Royal Netherlands Meteorological Institute (KNMI) constructed climate scenarios for the Netherlands based on global and regional climate models (Lenderink et al. 2007; Van den Hurk et al. 2007). In 2014 the KNMI scenarios for 2050 and 2085 were updated (Van den Hurk et al. 2014). Both global temperature rise and air circulation change were taken into account as steering parameters and used to create four scenarios. The recent update of the scenarios considered the CMIP5 climate model simulations (Taylor et al. 2012; http://ipcc. ch/report/ar5/) and used additional simulations using KNMI climate models EC-Earth and RACMO2 (Van den Hurk et al. 2014). KNMI distinguishes two important trends: temperature rise $(\mathrm{G}=$ moderate or $\mathrm{W}=$ warm $)$ and change in air circulation $(\mathrm{L}=$ low or $\mathrm{H}=$ high $)$, and combines these trends into four climate scenarios (Fig. 2).

The projected general trend is an increase in both precipitation and evaporation compared to the current climate (Fig. 2). Accordingly discharge through surface water and recharge of the groundwater are projected to increase during winter. The period with negative recharge will increase and become more negative, which will cause a decrease in groundwater level.

\subsection{Research Methodology}

Three redistribution scenarios were constructed in which existing groundwater extraction volumes are redistributed within the Veluwe area. The impact is assessed by the change in groundwater recharge and groundwater levels in the Veluwe area and for the groundwaterdependent ecosystems nearby the studied extraction sites.

First, the study area was modelled in a transient manner using current climate variables and the Dutch KNMI'14 climate scenarios as meteorological forcing for AZURE. The used spatial resolution was $250 \mathrm{~m}$. From the results steady-state mean groundwater recharges were derived, representative for the current climate and each of the four climate scenarios. Subsequently, the derived groundwater recharges and the modelled current recharge were used in steady-state calculations for the redistribution scenarios. Since the Veluwe has a thick unsaturated zone, a long spin-up period for the model is required to stabilize the unsaturated zone. Therefore the first 10 years were not included in the calculations of the steady-state recharge. Groundwater recharges of transient calculations were used in the steady-state calculations for the redistribution scenarios. The reference precipitation and evaporation were calculated using the mean values over the period 1991-2010. The datasets of the 2050 KNMI climate scenarios were used.

The reference situation and three scenarios were defined, based on the current situation in the Veluwe area (Table 1). The extraction sites AM, LC and EL are existing drinking water stations with a licensed extraction volume, where the possible impact on resp. NS, RB and FB is under discussion. To be able to deliver sufficient drinking water in the area, the drinking water company needs to consider redistributing the extracted volumes within the Veluwe area, without changing the total extraction volume. Therefore expansion of HO is considered. Not all theoretically possible scenarios were considered. The scenarios were selected because they 
Table 1 Summary of extraction volumes [million $\mathrm{m}^{3} / \mathrm{yr}$ ] and maximum groundwater level change $[\mathrm{m}]$ in the related groundwater-dependent ecosystems for the reference situation and redistribution scenarios $1-3$ under current climate or scenario GH2050, compared to groundwater levels in the reference situation under current climate (ref)

\begin{tabular}{|c|c|c|c|c|c|c|c|c|}
\hline \multirow[t]{2}{*}{ Redistribution scenarios } & \multirow[t]{2}{*}{ Climate scenario } & \multicolumn{4}{|c|}{$\begin{array}{l}\text { Extraction volumes in } \\
\text { million } \mathrm{m}^{3} / \mathrm{yr}\end{array}$} & \multicolumn{3}{|c|}{$\begin{array}{l}\text { Groundwater level } \\
\text { change in } \mathrm{m}\end{array}$} \\
\hline & & $\mathrm{AM}$ & EL & $\mathrm{LC}$ & $\mathrm{HO}$ & NS & FB & $\mathrm{RB}$ \\
\hline Reference situation & Current & 7.0 & 6.0 & 10.0 & 3.2 & ref & ref & ref \\
\hline Reference situation & $\mathrm{GH} 2050$ & 7.0 & 6.0 & 10.0 & 3.2 & $0.10-0.30$ & $0-0.20$ & $0.30-0.45$ \\
\hline 1 & Current & 5.5 & 6.0 & 10.0 & 4.7 & $0.05-0.40$ & 0 & 0 \\
\hline 2 & Current & 5.5 & 5.0 & 8.0 & 7.7 & $0.05-0.40$ & $0-0.05$ & 0 \\
\hline 3 & Current & 5.5 & 3.0 & 5.0 & 12.7 & $0.05-0.40$ & $0.05-0.15$ & $0.05-0.12$ \\
\hline 1 & GH2050 & 5.5 & 6.0 & 10.0 & 4.7 & $0.10-0.60$ & $0-0.20$ & $0.30-0.45$ \\
\hline 2 & GH2050 & 5.5 & 5.0 & 8.0 & 7.7 & $0.10-0.60$ & $0.10-0.30$ & $0.30-0.45$ \\
\hline 3 & GH2050 & 5.5 & 3.0 & 5.0 & 12.7 & $0.10-0.60$ & $0.15-0.35$ & $0.30-0.50$ \\
\hline
\end{tabular}

are possible without fully relocating drinking water extraction sites. The scenarios would, however, require a redistribution of licences and an enlargement of HO.

The expected impact of the proposed measures was an increase of groundwater levels in the groundwater-dependent ecosystems and thus improvement of the abiotic conditions in these areas, allowing to restore desiccated ecological values.

To limit the number of calculations of the redistribution scenarios, it was chosen to use the current climate and the GH scenario for 2050 (GH2050). Compared to the other scenarios GH2050 represents the most challenging climate scenario regarding the groundwaterdependent ecosystems (Figs. 2, 3). The impact of the scenarios on recharge and groundwater levels was studied for the model domain, the Veluwe area and the groundwater-dependent ecosystems NS, FB and RB.
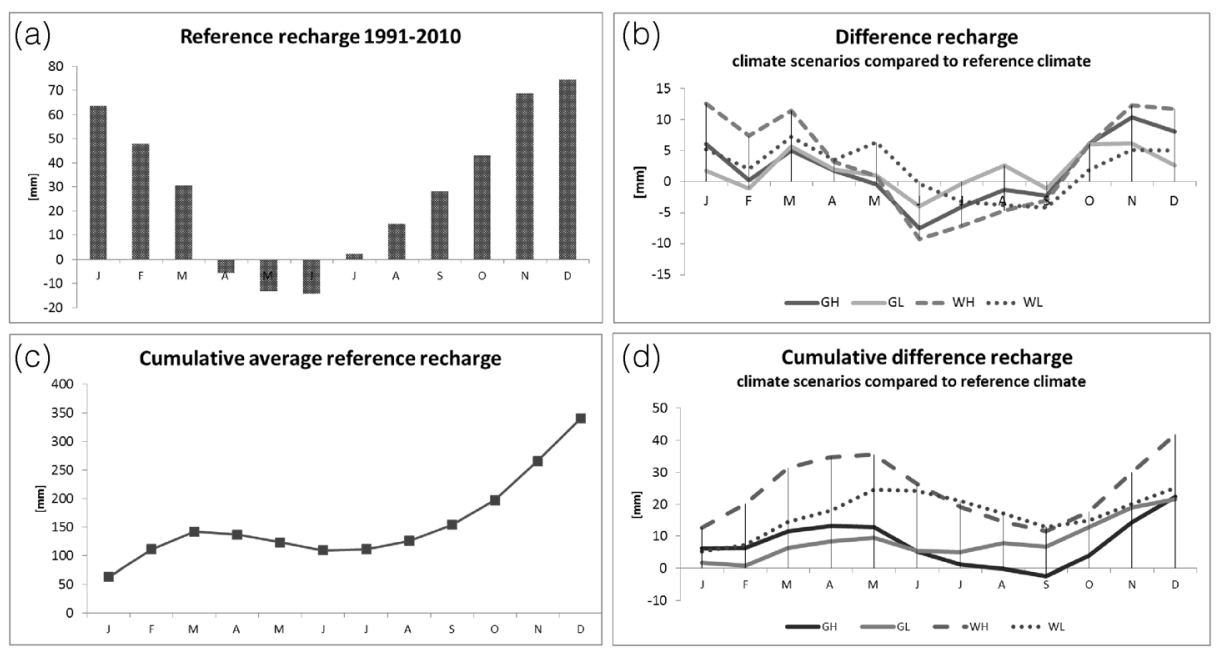

Fig. 3 Model results on groundwater recharge in the Veluwe area in [mm]: (a) average recharge in reference period (1991-2010); (b) net change in recharge in 4 KNMI'14 climate change scenarios 2050 (GL, GH, WL, WH) compared to reference recharge; (c) cumulative average recharge in reference period (1991-2010); (d) cumulative difference recharge according to the KNMI climate scenarios. Note: All results have been calculated in this study using the AZURE model and have been averaged for the Veluwe area 
(a)

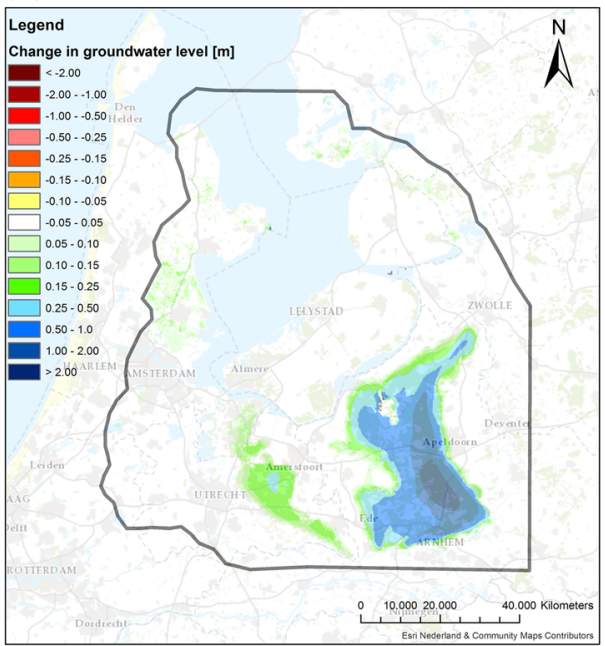

(b)

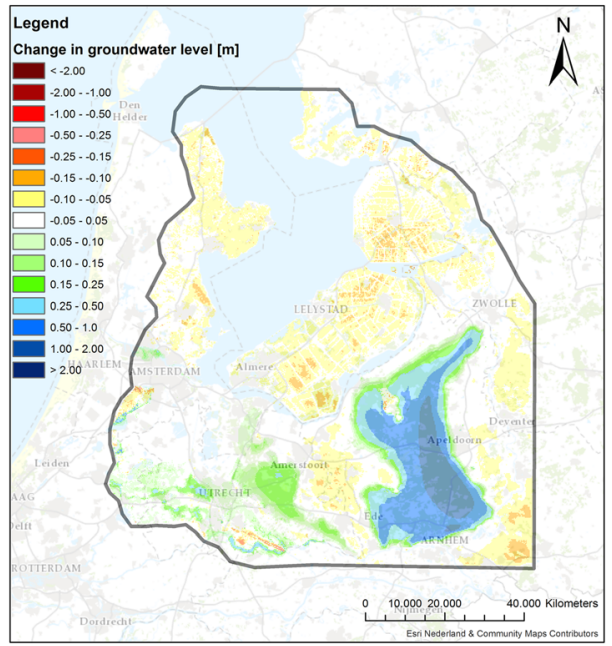

Fig. 4 Calculated change in groundwater level [m] for GH2050 in the AZURE model domain: (a) mean average groundwater level and (b) lowest groundwater level. The lowest groundwater levels have been calculated by averaging the three lowest levels for each year of the calculation period over the full calculation period as an indication for the driest situation

\section{Results}

\subsection{Climate Change Scenarios}

The current annual total groundwater recharge is $\sim 340 \mathrm{~mm}$ in the Veluwe area (Fig. 3). The reference recharge is projected to increase by 20 to $40 \mathrm{~mm}$ due to the KNMI' 14 climate change scenarios (Fig. 3). Model calculations confirm that in the Veluwe area the projected climate change will possibly contribute to an increase in the groundwater levels up to $2 \mathrm{~m}$ or more (Fig. 4a). A small area west of the Veluwe area shows a comparable impact, albeit to a lesser extent. This area is called the Utrechtse Heuvelrug and has hydrological characteristics similar to those of the Veluwe.

In contrast to the Veluwe area, the adjacent areas do have a surface water system on top of the groundwater system. In these areas vegetation is usually groundwater-dependent, because the groundwater level is close to the vegetation root zone. Results do not show a change in average groundwater levels in these areas, but do show a substantial impact to the average lowest groundwater levels (Fig. 4b; yellow and orange areas).

Vulnerable groundwater-dependent vegetation can disappear when the groundwater level falls below a certain level, even if only for a short time period. Therefore, the change in lowest groundwater level provides an indication of the potential risk of desiccation of groundwaterdependent ecosystems. Under GH 2050 the average lowest groundwater level in the Veluwe area and the Utrechtse Heuvelrug is projected to increase (Fig. 4b). In the groundwater system of the Veluwe the increase in winter precipitation will cause an increase in groundwater recharge. An increase in summer evaporation will only have a limited impact on the groundwater level, because the vegetation is rainwater dependent; the root zone of the vegetation is not related to the groundwater level, which is between 5 and $50 \mathrm{~m}$ or more below the soil surface. This explains that under climate change the groundwater level in the Veluwe area and the Utrechtse Heuvelrug area is projected to increase. 
Although under GH2050 the average groundwater level in the adjacent areas does not change, the lowest groundwater levels are projected to drop by $5-15 \mathrm{~cm}$ (Fig. $4 \mathrm{~b}$ ). This can be explained by two major hydrological differences compared to the Veluwe area. First, the surface water system discharges most of the additional winter precipitation, which limits the groundwater recharge in the area. Second, the groundwater level is close to the soil surface and vegetation is groundwater dependent. The increasing temperature caused by climate change will increase plant transpiration and thus will cause a decrease in groundwater levels in summer, possibly causing desiccation of vegetation (Runhaar et al. 1996; Runhaar et al. 1997). In contrast, the calculated lowest groundwater levels of NS, RB and FB show a projected increase under GH2050 (Table 1).

\subsection{Redistribution Scenarios}

The results of the steady state model runs show that redistribution of extraction volumes will affect the groundwater levels (Table 1, Fig. 5). In all redistribution scenarios the licensed extraction at $\mathrm{AM}$ is reduced by 1.5 million $\mathrm{m}^{3}$ per year compared to the reference situation. This is projected to cause a $0.4 \mathrm{~m}$ increase in groundwater levels. The shape of this area is caused by the resistance of the tilted clay layers, which force the groundwater to flow parallel to them. The size of the affected area decreases with an increase in the extraction volume at $\mathrm{HO}$. At $\mathrm{HO}$ the expansion of the extraction volume is estimated to cause a decline in groundwater level between $0.5 \mathrm{~m}$ (scenario 1 ) and $2 \mathrm{~m}$ (scenario 3 ).

Reduction of EL causes an increase in the groundwater level at FB between 0.05 (scenario 2 ) and $0.15 \mathrm{~m}$ (scenario 3). As the area surrounding FB has a surface water system that drains the area, the surface water discharge is likely to increase when the groundwater extraction is reduced. Therefore the groundwater is only partially recharged and the increase in groundwater level remains limited.

The results imply that a reduction of $\mathrm{LC}$ will have no (scenario 2 ) or only a limited (scenario 3 ) impact (max. $0.15 \mathrm{~m}$ ) to RB. This relatively small impact is caused by the distance between LC and $\mathrm{RB}$ and the complex hydrogeology of the area - a complicated tangle of tilted clay layers.

\subsection{Combined Scenarios}

The redistribution scenarios in combination with the climate change scenario GH2050 show an overall increase in the groundwater levels in the Veluwe area (Table 1, Fig. 5d). Simulation results, however, do indicate that the impact of climate change differs for each of the studied ecosystems compared to the projected impact of the redistribution scenarios. The impact of reduction of AM is twice the impact of climate change on the groundwater level at NS, whereas the impact of reduction of EL on FB is only half the impact of climate change. The effect of the reduction of LC is approximately one third of the effect of climate change on the groundwater level in RB. The projected impact of climate change on the groundwater levels compensates more than fully for the decrease in groundwater level as caused by the largest expansion of HO.

\section{Discussion}

The results of this study project a substantial increase of the average groundwater level in the Veluwe area under Dutch climate change scenarios, caused by the slowly responding 
(a)

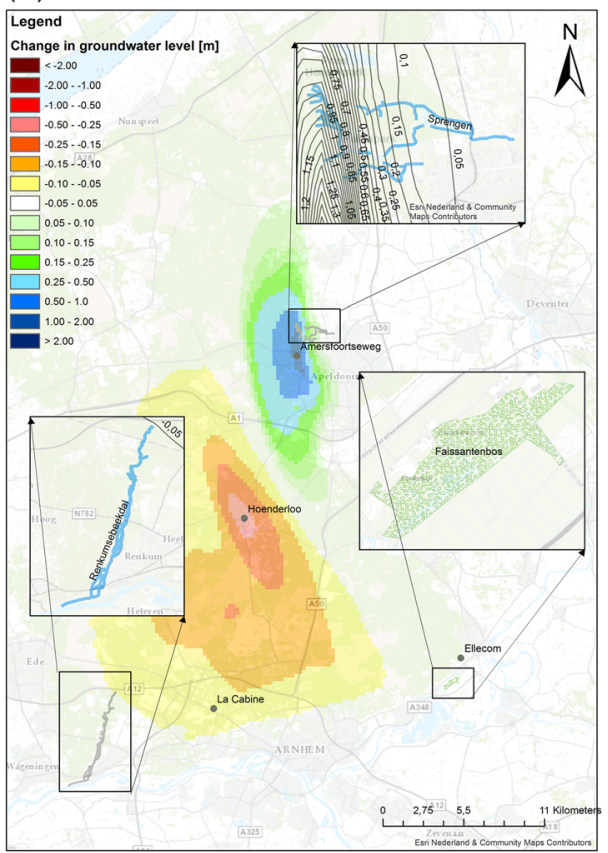

(c)

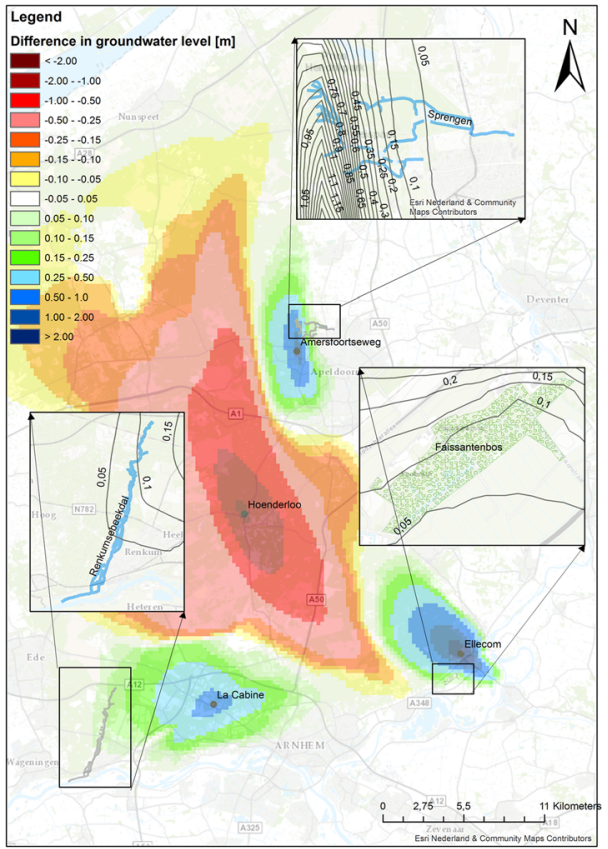

(b)

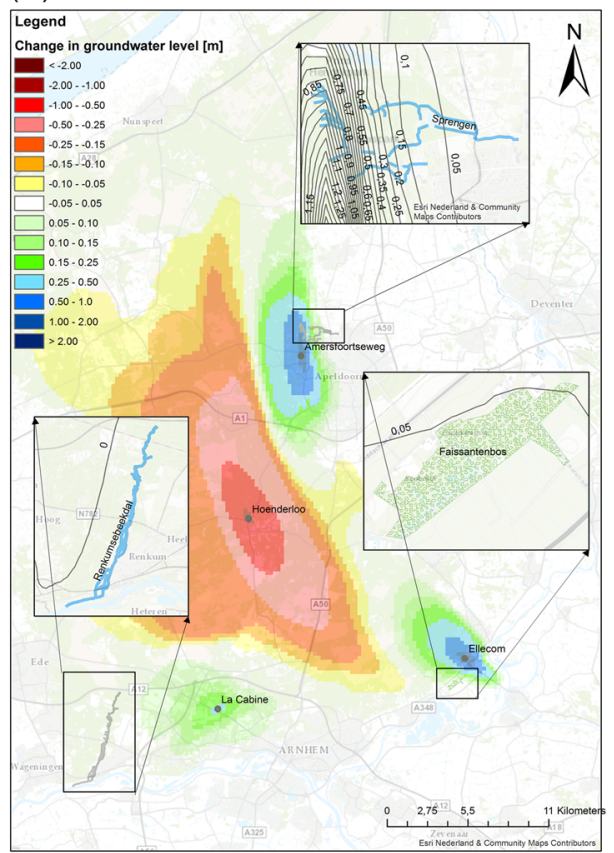

(d)

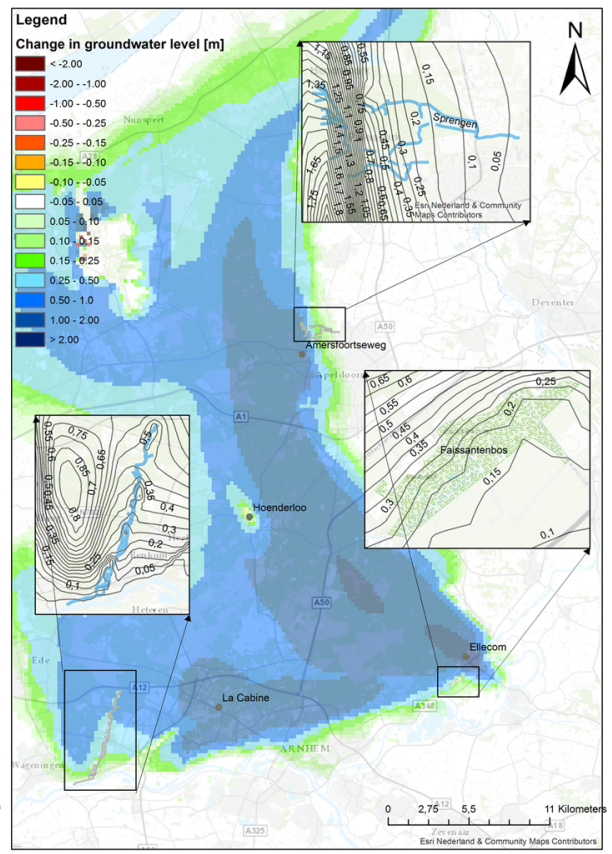

Fig. 5 Change in groundwater levels in [m] compared to the reference scenario in: (a) redistribution scenario 1 under current climate; (b) redistribution scenario 2 under current climate; (c) redistribution scenario 3 under current climate; (d) redistribution scenario 3 combined with climate scenario GH2050. Locally zoomed in to the studied groundwater-dependent ecosystems NS, FB and RB 
groundwater system. Even the ecologically more relevant average lowest groundwater level is projected to increase due to climate change.

In contrast, the average lowest groundwater level in the adjacent areas, with a combined surface water and groundwater system, is projected to decline because of the fast response of the system: excess precipitation in winter immediately discharges from the area by the surface water system and therefore causes only limited recharge of the groundwater system. In addition, the groundwater-dependent vegetation will cause an increase in evapotranspiration in summer, resulting in a significant decrease in groundwater levels.

Projected impacts of redistribution of groundwater extraction volumes differs depending on the hydrological relationship between the extraction site and the related ecosystem. The projected hydrological impact of partial reduction of the extractions LC and EL to the ecosystems of RB and FB is expected to be limited, especially compared to the impact of climate change. Partial redistribution of AM, however, is expected to clearly have an impact on NS.

\subsection{Climate Change Scenarios}

The projected general trend in climate change in the Netherlands is an increase in precipitation and evaporation compared to the current climate. Already over the last century precipitation has increased in the Netherlands, especially since 1980 (Buishand et al. 2013). The increase is probably caused by higher sea surface temperatures and changes in circulation, but could also be influenced by land use change and urbanization (Daniëls 2016). Global climate models especially indicate an increase in winter precipitation in the Netherlands related to the global mean temperature change; the projected change in mean summer precipitation is less conclusive (Lenderink et al. 2007). The model results indicate that the increases in winter precipitation are the main cause of the increased groundwater levels in the Veluwe area. As discussed above, most of the recent research on climate change in the Netherlands points in the same direction, i.e. an increase of winter precipitation. Therefore an increase in groundwater levels in the Veluwe area as a result of climate change is likely.

\subsection{Model}

Due to the complexity of groundwater systems and limited data availability it is often difficult to assess the impacts of climate change on groundwater systems. However, for this study it was possible to use AZURE, an existing, detailed hydrological model, already calibrated using extensive observational data. Because of the use of these detailed historical data, the model is expected to remain reliable in terms of near-future projections (De Lange and Borren 2014). On the other hand, the Veluwe area is considered a complex hydrological system, with steep hydraulic gradients, tilted clay layers and a thick unsaturated zone. Refinement of the model might improve the results, but is hard to accomplish (Verhagen et al. 2014; Wegehenkel 2009). The results of the model approximate the measured groundwater levels relatively well (De Lange and Borren 2014), although on average the simulated groundwater levels in the elevated areas are too low compared to the observed values, partially caused by the limited accuracy regarding the tilted clay layers. Nevertheless, the results of the model calculations are supported by expert knowledge of the hydrological characteristics of the system (De Lange and Borren 2014; Van Engelenburg et al. 2012). Taking these uncertainties into account, it is still reasonable to assume that groundwater levels in the Veluwe area will increase as a result of climate change. 
The groundwater level was used as indicator of the impact on related groundwater-dependent ecosystems, because of the uncertainties associated with direct and indirect effects caused by climate change. Climate change can potentially change the vegetation in response to increasing temperatures and shifts in precipitation (Kruijt et al. 2008). To which extent the vegetation will change also depends on soil moisture-climate interactions (Seneviratne et al. 2010). The projected increase of groundwater levels will influence the soil-water balance and could potentially change the vegetation. In case of increased rooting depth and/or a vegetation with higher transpiration rates, this could potentially result in lower groundwater levels. Due to this complexity of interactions of changes in temperature, precipitation and groundwater level, the dynamics of vegetation as a result of redistribution of groundwater extractions is hard to predict and thus hard to model.

Besides that, large parts of the Veluwe are considered to be dry areas, covered with vegetation that does not depend on groundwater. The vegetation in these areas is unlikely to be affected by a decrease in groundwater level, although the vegetation in this dry centre area is likely to change due to increasing temperature and shifts in precipitation. For these reasons the groundwater level changes are considered to be a strong indicator for the impact of climate change and partial redistribution of extractions on the Veluwe area.

\subsection{Redistribution}

Relocation of a drinking water extraction plant requires a large societal investment in the drinking water supply system and can take up to 10 years of preparation before becoming operational. Redistribution of drinking water extraction volumes between existing sites is a less far-reaching measure, although this also requires considerable changes in the drinking water supply system. This study focusses on redistribution between existing sites.

It is necessary to determine the necessity and impact before deciding on relocation or redistribution, and future developments such as climate change need to be taken into account. Based on the results of this study it can be concluded that at one location (AM) redistribution will have a strong positive impact on the related groundwater-dependent ecosystem (NS). Redistribution of LC and EL seems less urgent, because the impact of climate change largely exceeds the effect of a partial redistribution of the extraction volumes.

Recently, scenarios have been developed regarding future drinking water demand (Van der Aa et al. 2015). These scenarios were not taken into account, because the aim of this study was to assess the impact of redistribution with regard to the hydrological characteristics of the area within the currently licensed amount of groundwater within the Veluwe area.

\section{Conclusion}

The goal of this study was to assess the projected hydrological impact of climate change in the Veluwe area around the middle of the twenty-first century and to compare this to the impact of redistribution of existing drinking water extraction volumes in the Veluwe area by using a state-of-the-art hydrological model.

Therefore detailed climate change scenarios were combined with a detailed hydrological model. The results show that the hydrological characteristics of an area determine the impact of climate change: increasing groundwater levels in a slowly responding large aquifer without surface water system, as opposed to decreasing groundwater levels in fast responding combined groundwater-surface water systems. The results emphasize the importance of a thorough 
understanding of the hydrological system, which will help to avoid or refute incorrect assumptions on the supposed impacts. This is a valuable contribution to the scientific knowledge on the impact of climate change to groundwater resources.

After comparing the impact of climate change to the effect of redistribution of drinking water extractions, it can be concluded that for one of the extraction sites redistribution would have a strong positive impact even compared to the projected climate change impact. For the two other extraction sites redistribution seems less urgent because the projected impact of climate change is stronger than the impact of redistribution.

However, not only hydrological facts and figures determine this necessity. Also stakeholder opinions need to be taken into account (Van den Brink et al. 2008). A decision support method that combines the outcome of a hydrological study with the stakeholders' viewpoints could help to decide on adaptation measures. The results of this research will be used in a study on decision support regarding drinking water extraction sites for drinking water companies.

Open Access This article is distributed under the terms of the Creative Commons Attribution 4.0 International License (http://creativecommons.org/licenses/by/4.0/), which permits unrestricted use, distribution, and reproduction in any medium, provided you give appropriate credit to the original author(s) and the source, provide a link to the Creative Commons license, and indicate if changes were made.

\section{References}

Broers HP, Lijzen JP (2014) Afwegingen bij het gebruik van grondwater en de ondergrond: Deltares

Buishand TA, De Martino G, Spreeuw JN, Brandsma T (2013) Homogeneity of precipitation series in the Netherlands and their trends in the past century. Int J Climatol 33(4):815-833. https://doi.org/10.1002/joc.3471

Carmona G, Varela-Ortega C, Bromley J (2013) Supporting decision making under uncertainty: Development of a participatory integrated model for water management in the middle Guadiana river basin. Environ Model Softw 50:144-157. https://doi.org/10.1016/j.envsoft.2013.09.007

Daniëls EE (2016) Land surface impacts on precipitation in the Netherlands. (PhD), Wageningen University, Wageningen

De Graaf IEM, van Beek RLPH, Gleeson T, Moosdorf N, Schmitz O, Sutanudjaja EH, Bierkens MFP (2017) A global-scale two-layer transient groundwater model: Development and application to groundwater depletion. Adv Water Resour 102:53-67. https://doi.org/10.1016/j.advwatres. 2017.01.011

De Lange W, Borren W (2014) Grondwatermodel AZURE versie 1.0. Deltares, Delft, the Netherlands

De Lange WJ, Prinsen GF, Hoogewoud JC, Veldhuizen AA, Verkaik J et al (2014) An operational, multi-scale, multi-model system for consensus-based, integrated water management and policy analysis: The Netherlands Hydrological Instrument. Environ Model Softw 59:98-108

Delsman J, Veldhuizen A, Snepvangers J (2008) Netherlands Hydrological Modeling Instrument. Paper presented at the Proceedings of international congress MODFLOW and more: ground water and public policy. Golden, CO

Gehrels JC (1999) Groundwater level fluctuations : separation of natural from anthropogenic influences and determination of groundwater recharge in the Veluwe area, the Netherlands. Gehrels, [S.1.]

Gleeson T, Alley WM, Allen DM, Sophocleous MA, Zhou Y, Taniguchi M, VanderSteen J (2012a) Towards sustainable groundwater use: setting long-term goals, backcasting, and managing adaptively. Ground Water 50(1):19-26. https://doi.org/10.1111/j.1745-6584.2011.00825.x

Gleeson T, Van der Steen J, Sophocleous MA, Taniguchi M, Alley WM, Allen DM, Zhou Y (2010) Groundwater sustainability strategies. Nat Geosci 3(6):378-379. https://doi.org/10.1038/ngeo881

Gleeson T, Wada Y, Bierkens MF, Van Beek LP (2012b) Water balance of global aquifers revealed by groundwater footprint. Nature 488(7410):197-200. https://doi.org/10.1038/nature11295

Harbaugh AW, Banta ER, Hill MC, McDonald MG (2000) MODFLOW-2000, the US Geological Survey Modular Ground-water Model - User guide to Modularization Concepts and the Ground-water Flow Process: U.S. Geological Survey, Reston, Virginia

Hekman A, Van Manen H, De Lange W (2014) AZURE: Innoveren in de 'gouden driehoek'. H2O-online, 2014(24 January), 6

Kloosterman RA (2015) Understanding the Locks-ins of Drinking Water Systems IWA LESAM 2015. Yokohama

Kruijt B, Witte J-PM, Jacobs CMJ, Kroon T (2008) Effects of rising atmospheric CO2 on evapotranspiration and soil moisture: A practical approach for the Netherlands. J Hydrol 349(3-4):257-267. https://doi.org/10.1016 j.jhydrol.2007.10.052 
Kumar R, Musuuza JL, Van Loon AF, Teuling AJ, Barthel R et al (2016b) Multiscale evaluation of the Standardized Precipitation Index as a groundwater drought indicator. Hydrol Earth Syst Sci 20(3):11171131. https://doi.org/10.5194/hess-20-1117-2016

Kumar V, Del Vasto-Terrientes L, Valls A, Schuhmacher M (2016a) Adaptation strategies for water supply management in a drought prone Mediterranean river basin: Application of outranking method. Sci Total Environ 540:344-357. https://doi.org/10.1016/j.scitotenv.2015.06.062

Lenderink G, van Ulden A, van den Hurk B, Keller F (2007) A study on combining global and regional climate model results for generating climate scenarios of temperature and precipitation for the Netherlands. Clim Dyn 29(2-3):157-176. https://doi.org/10.1007/s00382-007-0227-z

Menke H, Meijer J (2007) Veluwse beken en sprengen : een uniek landschap. Matrijs, Utrecht

Person M, McIntosh J, Bense V, Remenda VH (2007) Pleistocene hydrology of North America: The role of ice sheets in reorganizing groundwater flow systems. Rev Geophys 45(3):1-28. https://oi.org/10.1029/2006 $\operatorname{rg} 000206$

Runhaar HJ, Witte JPM, Verburg PH (1997) Ground-water level, moisture supply, and vegetation in the Netherlands. Wetlands 17(4):11

Runhaar J, Van Gool C, Groen C (1996) Impact of hydrological changes on nature conservation areas in the Netherlands. Biol Conserv 76(3):269-276

Rutten MG (1960) Ice-pushed ridges, permafrost and drainage. Am J Sci 258(April 1960):5

Seneviratne SI, Corti T, Davin EL, Hirschi M, Jaeger EB et al (2010) Investigating soil moisture-climate interactions in a changing climate: A review. Earth Sci Rev 99(3-4):125-161. https://doi.org/10.1016/j.earscirev.2010.02.004

Skaggs RW, Breve MA, Gilliam JW (1994) Hydrologic and water quality impacts of agricultural drainage*. Crit Rev Environ Sci Technol 24(1):1-32. https://doi.org/10.1080/10643389409388459

Staben N, Nahrstedt A, Merkel W (2015) Securing safe drinking water supply under climate change conditions. vol. 15. Water Science and Technology: Water Supply. IWA Publishing, London, pp 1334-1342

Taylor KE, Stouffer RJ, Meehl GA (2012) An overview of CMIP5 and the experiment design. Bull Am Meteorol Soc 93(4):485-498

Van den Brink C, Zaadnoordijk WJ, van der Grift B, Ruiter PCD, Griffioen J (2008) Using a groundwater quality negotiation support system to change land-use management near a drinking-water abstraction in the Netherlands. (Characterization and apportionment of nutrient and sediment sources in catchments.) $\mathrm{J}$ Hydrol 350(3/4):339-356. https://doi.org/10.1016/j.jhydrol.2007.10.046

Van den Hurk B, Siegmund P, Klein Tank A (2014) KNMI'14: Climate Change scenarios for the 21st Century A Netherlands perspective. Scientific Report (pp 115). De Bilt, the Netherlands: KNMI

Van den Hurk B, Tank AK, Lenderink G, Ulden A, Oldenborgh GJ et al (2007) New climate change scenarios for the Netherlands. Water Sci Technol 56(4):27-33. https://doi.org/10.2166/wst.2007.533

Van der Aa NGFM, Tangena BH, Wuijts S, De Nijs ACM (2015) Scenario's drinkwatervraag 2015-2040 en beschikbaarheid bronnen; verkenning grondwatervoorraden voor drinkwater. (RIVM-Rapport 2015-0068). Bilthoven

Van der Knaap YAM, De Graaf M, Van Ek R, Witte J-PM, Aerts R, Bierkens MFP, Van Bodegom PM (2014) Potential impacts of groundwater conservation measures on catchment-wide vegetation patterns in a future climate. Landsc Ecol 30(5):855-869. https://doi.org/10.1007/s10980-014-0142-8

Van Engelenburg J, Spek T, Van Doorn A (2012) Is een stuwwal modelleerbaar? H2O(9), 4

Van Walsum PEV, Groenendijk P (2008) Quasi Steady-State Simulation of the Unsaturated Zone in Groundwater Modeling of Lowland Regions. Vadose Zone J 7(2):769. https://doi.org/10.2136/vzj2007.0146

Van Walsum PEV, Veldhuizen AA (2011) Integration of models using shared state variables: Implementation in the regional hydrologic modelling system SIMGRO. J Hydrol 409(1-2):363-370. https://doi.org/10.1016/j. jhydrol.2011.08.036

Verhagen F, Spek T, Witte F, Voortman B, Moors E et al (2014) Expertdialoog de Veluwe: Begrijpen we het watersysteem? Stromingen 20(3):15

Wegehenkel M (2009) Modeling of vegetation dynamics in hydrological models for the assessment of the effects of climate change on evapotranspiration and groundwater recharge. Adv Geosci 21:7

Witte J-PM, Bartholomeus RP, Van Bodegom PM, Cirkel DG, Van Ek R et al (2014) A probabilistic ecohydrological model to predict the effects of climate change on natural vegetation at a regional scale. Landsc Ecol 30(5):835-854. https://doi.org/10.1007/s10980-014-0086-Z

Witte JPM, Runhaar J, Van Ek R, Van der Hoek DCJ, Bartholomeus RP et al (2012) An ecohydrological sketch of climate change impacts on water and natural ecosystems for the Netherlands: bridging the gap between science and society. Hydrol Earth Syst Sci 16(11):3945-3957. https://doi.org/10.5194/hess-16-3945-2012

Yousefpour R, Didion M, Jacobsen JB, Meilby H, Hengeveld GM, Schelhaas M-J, Thorsen BJ (2015) Modelling of adaptation to climate change and decision-makers behaviours for the Veluwe forest area in the Netherlands. Forest Policy Econ 54:1-10. https://oi.org/10.1016/j.forpol.2015.02.002

Zwolsman GJ, Cirkel DG, Hofs B, Kardinaal E, Learbuch K et al (2014) Risico's van klimaatverandering voor de drinkwatersector. KWR, BTO 2014:027 